\title{
3 Boyutlu Yazıcı Sistemine Monte Edilmiş TIG Kaynak Mekanizması
}

\author{
TIG Welding Mechanism Mounted on 3D Printing System
}

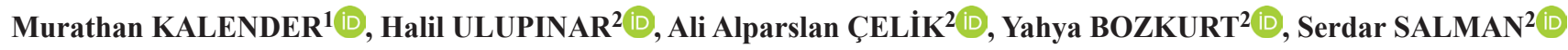 \\ ${ }^{1}$ Marmara Üniversitesi, Teknoloji Fakültesi, Makine Mühendisliği Bölümü, İstanbul, 34722, Türkiye \\ ${ }^{2}$ Marmara Üniversitesi, Teknoloji Fakültesi, Metalurji ve Malzeme Mühendisliği Bölümü, İstanbul, 34722, Türkiye
}

Öz

Tungsten Inert Gas (TIG) kaynak tekniği günümüzde en çok kullanılan kaynak tekniği yöntemlerinden biridir. Yöntemde genellikle argon gazı kullanıldığı için argon kaynağı olarak da bilinmektedir. Ergimeyen bir elektrot çeşidi olan tungsten elektrot sayesinde stabil bir ark oluşturulmaktadır. TIG kaynağı yöntemi ile kaynak dikişi, kaliteli ve cürufsuz şekilde meydana gelmektedir. Diğer kaynak yöntemlerine göre ilerleme hızı daha düşük olan TIG kaynak yöntemi ince ve hassas malzemeler, paslanmaz çelikler, alüminyum, bakır gibi malzemelerin kaynağında kullanılmaktadır. TIG kaynak tekniğinde yüksek sıcaklık girdisi, malzemelerin çarpılması, torçtaki ve ilave teldeki el hareketi vb. gibi birtakım zorluklar bulunmaktadır. Bu zorluklarla karşılaşıldığında kaynak bölgesinde yüksek 1sı girdisi, yetersiz nüfuziyet, kaynak oluğu vb. hatalar oluşmaktadır. Ayrıca TIG torcunun kaynak yapılacak yüzeyden sapmaması, kaynak yapılacak numunelerin stabil olması ve ark kararlığı kaynak kalitesi için son derece önemli etkenlerdir. Bu nedenle kaynak dikişiyle beraber kaynaktaki el hareketi de önemli bir parametredir. Havacılık ve uzay sanayinde kullanılan ve kaynak tekniği ile birleştirilen malzemelere baktığımızda yüksek maliyetleri ürünler olduğu görülmektedir. Dolayısıyla bu parçalar üzerinde hata yapma olasılığı mümkün olduğunca düşük olması gerekir. Bu tür parçalarda, dikiş hareketleri ve kaynak hızları, parçanın mekanik özelliklerine doğrudan etki etmektedir. Bu çalışmada; ince ve hassas malzemelerin kaynak işlemini 3 boyutlu yazıcı tekniği ile gerçekleştirecek ve kaynaktaki dikiş sağlamlığını, ark kararlığını ve gerekli nüfuziyeti oluşturabilecek bir makine prototipi üretilmiştir. Geleneksel lineer kaynak dikişi hareketinin yanında 3 boyutlu yazıcının eksenlerine bağlı farklı dikiş türleri ile de parçalarda kaynak işlemi gerçekleştirilebilir. Sistemdeki Z ekseni ise kaynaktaki ark boyunu ayarlayarak kaynaktaki ark kararlılığını sağlamıştır. Ayrıca kaynak parçalarındaki yüksek ısı girdisi nedeniyle oluşacak çarpılmalar, 3 eksen kaynak mekanizmasının tablasındaki ısı iletim katsayısı uygun olan malzemeler ile giderilmiştir.

Anahtar Kelimeler: 3B Yazıc1, Ergitmeli Kaynak, Gazaltı Kaynak, Kaynak Teknolojileri, TIG Kaynağı.

\begin{abstract}
Tungsten Inert Gas (TIG) welding technique is one of today's popular welding techniques. It is also known as argon welding because of argon gas usage during the welding process. Tungsten electrode which is a kind of non-melting electrode provides a stable arc generation. With the TIG welding method, quality and slag-free welding seam occurs. TIG welding method, which has a lower feed rate compared to other welding methods, is used for welding thin and sensitive materials, stainless steels, aluminum, copper. In TIG welding technique, there are a number of difficulties such as high temperature input, material distortion, and hand movement in the torch and additional wire. High heat input in the welding zone, insufficient penetration, welding groove etc. imperfections occur when these difficulties are encountered. In addition, none deviation of TIG torch from the welding surface, the uniformity of surface of welding samples and the arc stability are extremely important factor for welding quality. Hand movement during welding is an important parameter as well as welding seam quality When we consider about the welded materials used for the aviation and aerospace industry, these are high cost products. So the probability of making mistakes on these parts should be as low as possible. In such parts, sewing movements and welding speeds affect directly the mechanical properties of the part. In this study; a machine prototype has been produced that will perform the welding process of fine and sensitive materials via 3D printer technique with required seam strength, arc stability and necessary penetration at the welding. Besides traditional linear sewing movements, different sewing movements connected with axis of 3D printer can be achieved to weld parts. The $\mathrm{Z}$ axis in the system has maintains the arc stability by adjusting the arc length. In addition, distortions due to the high heat input in the welding parts are eliminated via using 3D printer table materials whose heat conduction coefficient is suitable.
\end{abstract}

Keywords: 3D Printer, Melt Welding, Gas Welding, Welding Technology, TIG Welding. 


\section{GIRIS}

Gelişen teknolojiyle beraber yeni uygulamalar ve yeni malzemeler ortaya çıkmaktadır. Bununla beraber katmanlı üretim yöntemleri de sürekli olarak geliştirilmektedir. $\mathrm{Bu}$ teknolojinin daha erişilebilir hale gelmesinin ana nedenlerinden biri, üreticilere yeni 3 boyutlu (3B) bask1 cihazları geliştirme olanağı sağlayan önceki patentlerin sona ermesidir. Son gelişmeler 3B yazıcıların maliyetini düşürmüştür ve böylece okullarda, evlerde, kütüphanelerde ve laboratuvarlarda yaygınlaşarak uygulama alanında geniş bir alana yayılmıştır. 3B imalat teknolojisi mühendislik, mimarlık ve endüstriyel tasarım alanlarında kullanılmaktadır. Eklemeli imalat sadece prototipler üretmek için değil, aynı zamanda makine parçaları ve kalıp takımları gibi ürünler elde etmek için de kullanılabilir [1-2]. 3B yazıcı teknolojisinin farklı sektörler içerisinde eklemeli imalatın dağılımı Şekil 1'de gösterilmiştir.

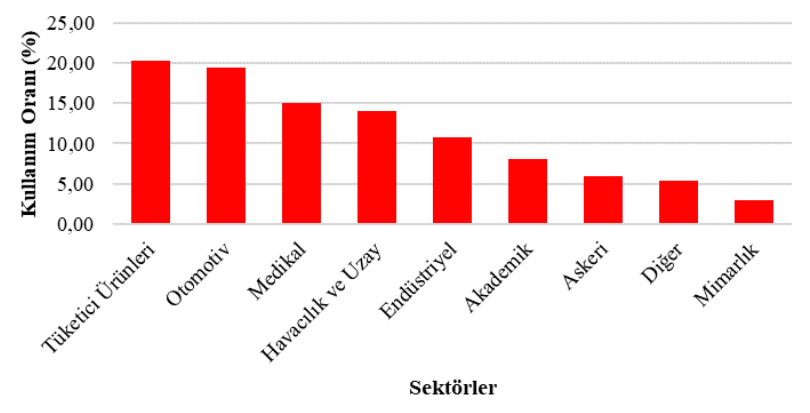

Şekil 1. Farklı sektörler içerisinde eklemeli imalatın dağılımı [1]

Metal baskıyı yaygınlaştırmak için bazı teknikler geliştirilmektedir. Geliştirilen bu yöntemlerden biri ise bir kaynak robotu, metal bir yüzey üzerine kaynak yapar gibi metal yığmaktadır. Metal yapıları 3B yazıcılarda yazdırmak için pahalı bir teknolojiyi satın alıp kullanmak yerine bu yeni geliştirilen yöntem sayesinde büyük yatırım masrafları ortadan kalkmaktadır [3].

TIG (Tungsten Inert Gas) kaynağı, kullanım açısından geniş yelpazesi olan birleştirme yöntemidir. Demir esaslı ve demir dışı metal ve alaşımların çok büyük bir kısmının birleştirilmesinde kullanılabilmektedir. Ayrıca bütün kaynak pozisyonlarında sağlıklı sonuçlar alınabilmektedir. TIG kaynağı ince levhaların kaynağında çok başarılı sonuçlar vermesinin yanı sıra kalın parçaları kolaylıkla birleştirebilmektedir. Ergimeyen tungsten elektrot kullanılması, gerektiğinde esas metal ergitilerek, ilave kaynak metaline olan gereksinimi de ortadan kaldırmaktadır. Ayrıca kaynak banyosu kontrol edilebildiği için banyo üzerinde cüruf oluşumu engellenerek dikişte cüruf kalma tehlikesi ortadan kalkmaktadır. [4]. Kaynaklı birleştirmenin mekanik özellikleri göz önüne alındığında, yapılan kaynak işleminin türü, ısı girdisi, kaynak pasosu, kaynak hızı ve dikiş hareketi gibi parametreler, kaynağın mikro yapısını etkileyerek kaynak bölgesinin özelliklerini değiştirmektedir. Bu parametreler uygun seçilmediğinde veya sağlıklı uygulanmadığında ana metaller olumsuz etkilenmekte olup kaynak dayanımını düşürmektedir [5-6].

Kaynak ergime bölgesindeki kaynak dikişi, kaynak metalinin katılaşması sırasında bulunduğu durumdan dolayı kaba taneli yapıyı da içerir. Bu durum kaynak bölgesinin dayanımını düşürüp kaynak edilen numunede çatlak oluşma ihtimalini arttırır. Çok fazla 1sı girdisi oluşmasında kaynak dikişi üzerindeki soğuma kontrol altına alınmalıdır. Kontrol altına alınan sıcaklık katılaşma mikro yapısı üzerinde de etki sağlayacaktır. TIG torcunun kaynak yapılacak yüzeyden sapmaması, kaynak yapılacak numunelerin stabil olması ve ark kararlığı kaynak kalitesi için son derece önemli etkenlerdir. Bu nedenle kaynak dikişiyle beraber kaynaktaki el hareketi de önemli bir parametredir [7-9].

$\mathrm{Bu}$ çalışmanın amacı ince ve hassas malzemelerin kaynak işlemini 3B yazıcı tekniği ile gerçekleştirip, kaynaktaki gerekli dikiş sağlamlığını, ark kararlılığını ve nüfuziyeti oluşturabilmektir. Sistemdeki X ve Y ekseni kaynak torcunun düzlem üzerindeki dikiş hareketlerini ve kaynak hızını sağlayacaktır. Bu sistem birleştirilecek parçalar üzerinde sadece lineer bir dikiş atmayıp, geleneksel dikiş hareketlerinden farklı olarak sistemde belirlenen dikiş türleriyle de kaynak yapabilecektir. Sistemdeki $\mathrm{Z}$ ekseni ise kaynaktaki ark boyunu ayarlayarak kaynaktaki ark kararlılığını sağlayacaktır. Kaynak mekanizması amacına uygun kullanılmak üzere paslanmaz çelik, bakır ve alüminyum üzerinde yapılan kaynaklarda, kaynak hızı parametresi belirlemede de yardımcı olacaktır.

\section{TIG KAYNAK YÖNTEMI}

TIG kaynak yöntemi kaynak kalitesi olarak diğer kaynak yöntemlerine göre daha estetik ve temiz bir dikiş görüntüsü sunmaktadır [10]. TIG kaynak yöntemi ile demir dışı metallerin kaynağında nüfuziyetli bir birleştirme oluşturulduğu gibi paslanmaz çeliklerin kaynağında da son derece kaliteli ve pürüzsüz bir kaynak dikişi sağlanmaktadır. TIG kaynak yönteminde ergimeyen elektrot adı verilen elektrot kullanılmaktadır ve ana metal ile elektrot arasında oluşan ark sayesinde birleştirme gerçekleştirilmektedir. Ark bölgesi atmosfer ortamındaki istenmeyen gazlardan soy gazlar veya alaşım gazlar sayesinde korunmaktadır [11]. TIG kaynak yönteminin diğer kaynak yöntemlerine göre birçok avantajı olduğu gibi bazı olumsuz etkileri de bulunmaktadır. 
Özellikle ilerleme hızının diğer yöntemlerine göre yavaş olması toplam verimi düşürdüğü için bu kaynak yönteminin seri üretimde kullanılabilirliği kısıtlanmıştır. Bununla beraber kalın kesitli malzemelerde tek pasoda geçişin yetersiz nüfuziyet oluşturması bu yöntemin daha çok ince parçaların kaynaklı birleştirmelerinde kullanılmasına neden olmuştur [12]. TIG kaynağının şematik gösterimi Şekil 2‘de gösterilmiştir.

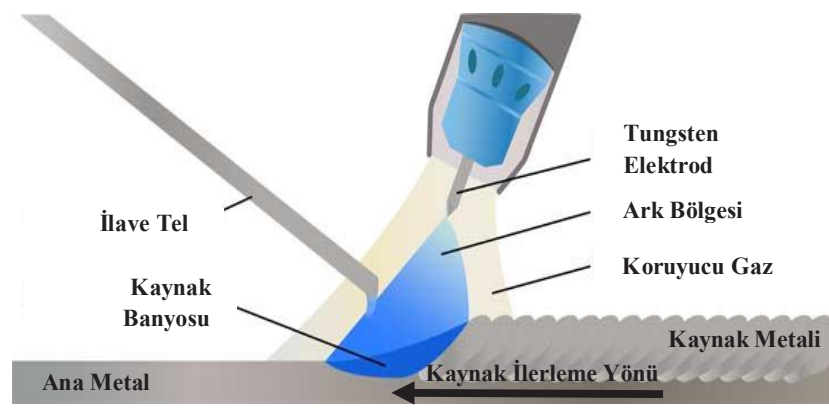

Şekil 2. TIG kaynağının şematik gösterimi [13]

Diğer kaynak yöntemlerinde olduğu gibi TIG kaynak yönteminde de malzemenin cinsine en uygun kaynak parametreleri belirlenmeli ve belirlenen bu parametrelere kaynak esnasında bağlı kalınması gerekmektedir. TIG kaynaklı birleştirme işlemi sırasında uygulanan çeşitli değişkenler kaynak dikişinin geometrik yapısının kalitesinde önemli olduğu gibi kaynak metalinin mikro yapı ve mekanik özelliklerini de önemli ölçüde etkilemektedir [14]. İlerleme yönü ve hızı, torc tutuş açısı, kaynak amperi, koruyucu gaz cinsi, ark mesafesi, kaynak gerilimi ve birleştirme dizaynı gibi çeşitli parametrelerin TIG kaynak banyosunun geometrik görüntüsünde önemli ölçüde fark yarattığı bilinmektedir. Özellikle ilerleme hızı ve kaynak akımı bu parametrelerden en önemlileri olup kaynak genişliğini, nüfuziyet derinliğini, 1S1 girdisi miktarını direkt olarak etkilemektedir. TIG kaynak makinelerinde bulunan darbeli ark (pulse) yöntemi kullanıldığında birleştirme esnasında nüfuziyet miktarı önemli ölçüde artarken, malzemede oluşan toplam 1sı girdisi miktarı minimum seviyede kalmaktadır [15]. Ayrıca kaynak s1rasında numunelerin titreşimini önlemek için uygun kelepçe ve fikstürler kullanılmalıdır [16]. Bu yöntem ile ince kesitli parçalar distorsiyona maruz kalmadan düşük 1sı girdisi ile optimum nüfuziyet sağlanarak birleştirilmektedir. Şimdiye kadar yapılan çalışmalar da birçok araştırmacı farklı kaynak yöntemleri, birleştirme dizaynları ve parametreler kullanarak kaynaklı birleştirme işlemini gerçekleştirmiş̧ir. Seçilen parametrelerin kaynak metalinde oluşturduğu nüfuziyet derinliği ve esas metaldeki distorsiyon miktarı incelenmiştir
[17]. Bileşiğinde aynı kimyasal kompozisyonları barındıran paslanmaz çeliklerin kaynağında ilerleme hızı, tutuş açısı, kaynak akımı gibi parametrelerde meydana gelen az miktarda farkl1lıklar bile kaynak esnasında banyodaki metal akış düzenini önemli ölçüde etkilemektedir [18]. TIG kaynağında kullanılan koruyucu gaz türünün kaynak kompozisyonundaki nüfuziyet derinliği ve genişliğindeki etkisinin büyük olduğu gözlemlenmiştir [15].

\section{YÖNTEM}

$\mathrm{Bu}$ çalışmada; ince ve hassas malzemelerin kaynak işlemini 3B tekniği ile gerçekleştirecek ve kaynaktaki dikiş sağlamlığını, ark kararlığını ve gerekli nüfuziyeti oluşturabilecek bir makine prototipi üretilmiştir. Bu sistem ile birleştirilecek parçalar üzerinde sadece lineer bir dikiş atmayıp, geleneksel dikiş hareketlerinden farklı olarak yazıcı sistemindeki eksen hareketleriyle dikiş türleriyle de kaynak yapılabilmektedir. Sistemdeki Z ekseni ise kaynaktaki ark boyunu ayarlayarak kaynaktaki ark kararlılığını sağlamıştır. Ayrıca kaynak parçalarındaki yüksek 1sı girdisi nedeniyle oluşacak çarpılmalar, 3 eksen kaynak mekanizmasının tablasındaki isı iletim katsayısı uygun olan malzemeler ile giderilmiştir. Çalışmada prototip cihaza Magmaweld Monotig 160ip tipi kaynak makinesi bağlanmıştır.

3B yazıcının kaynak mekanizması Autodesk Fusion 360 ve SolidWorks programı ile tasarlanmıştır. Çalışmada tasarlanan ve üretilen yazıcının Autodesk Fusion 360 yazılımındaki görüntüsü Şekil 3'te verilmiştir. Hazırlanan mekanizmanın genel özellikleri Tablo 1'de gösterilmiştir.

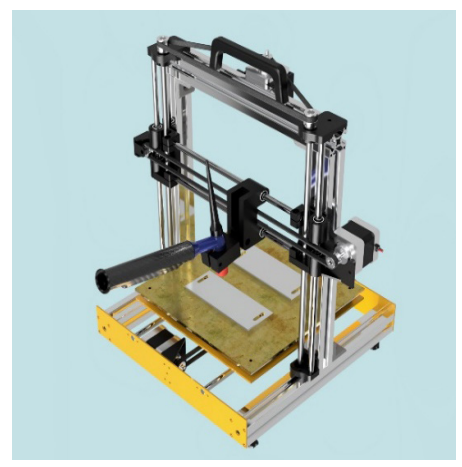

Şekil 3. Mekanizmanın Autodesk Fusion 360 programındaki görüntüsü

Tablo 1. Hazırlanan mekanizmanın genel özellikleri.

\begin{tabular}{|l|l|}
\hline Kaynak Tablası Ölçüleri & 230x230mm \\
\hline Fikstür Malzemesi & Pirinç ve alüminyum plaka. \\
\hline Kaynaklanabilir Sac Kalınlığı & $<2 \mathrm{~mm}$ \\
\hline Diğer Özellikler & $\begin{array}{l}\text { Taşınabilir, ergonomik, özel fikstür } \\
\text { tasarımı. }\end{array}$ \\
\hline
\end{tabular}


Mekanizma ince sac malzemelerin kaynatılması amacıyla tasarlanmış olup, montajların tamamlanmış halindeki gövde ölçüleri mm cinsinden Şekil 4’te gösterilmiştir.

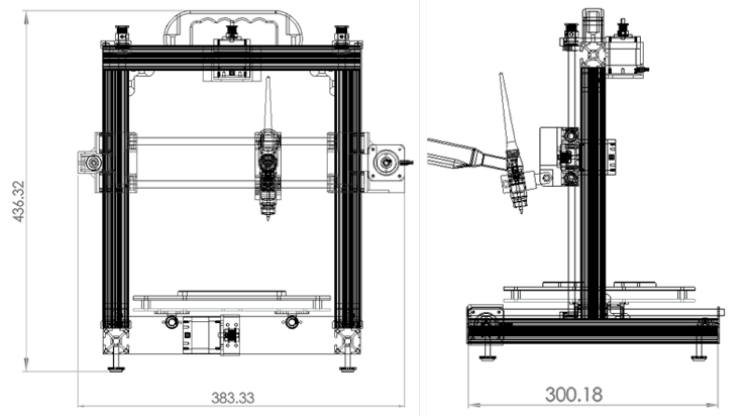

Şekil 4. Mekanizmanın gövde ölçüleri

\section{TIG Kaynak Mekanizması Prototipinin Mekanik Montajı}

TIG Kaynak mekanizma montajında, montaj kısmı mekanik ve elektronik olmak üzere iki kısımda tamamlanmıştır.

\section{Gövde montajı}

Öncelikle tedarik edilen malzemeler içerisinde gövdeyi inşa etmek için önemli olan alüminyum sigma profiller birleştirilmiştir. Ana gövde bu şekilde oluşturmuştur. Alüminyum sigma profiller köşe bağlantı elemanları ile birlikte birbirlerine montaj edilmiştir. Böylelikle daha rijit bir gövde oluşturulmuştur. Gövde için gereken alüminyum sigma profiller $30 \mathrm{~mm}$ x $30 \mathrm{~mm}$ genişliğinde $300 \mathrm{~mm}$ boyundadır. Sonrasında gövdeyi sabitlemeye yarayan, CNC'de imal edilmiş yataklar sabitlenmiştir. Şekil 5'te çalışmada kullanılan TIG kaynak mekanizması prototipi için hazırlanan gövde gösterilmiştir. Yazıcı gövdesi inşası temel hatları ile bitirilip ve sonrasında hareket eksenleri ve eksen taşıyıcı parçalar montajlanmıştır. Alüminyum sigma profilde boşluk kalan bölgelerin temizliği açısından kanal fitilleri monte edilmiştir. Gövde sonrasında kademeli olarak sağlamlaştırlarak civatalar kontrol edilmiştir. Titreşim sönümleyici 4 adet plastik ayak, alüminyum sigma profillerden oluşan gövdeye M6 civatalar ile monte edilmiştir.

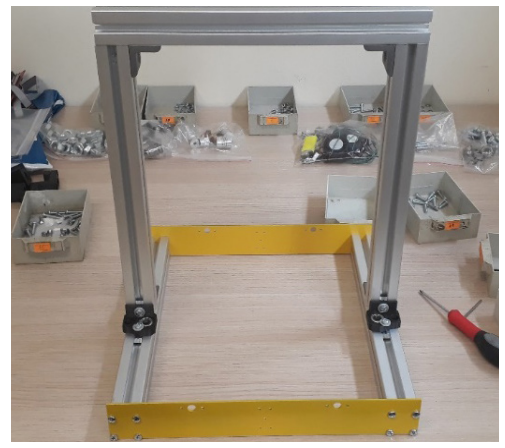

Şekil 5. Alüminyum sigma profiller ile oluşturulan gövde

\section{Hareket eksenleri montajı}

Çalışmada z ekseni önemli parçalarından olan kılavuz millerin montajı yapılmıştır. Üst kılavuz miller için doğrudan alüminyum sigma profiller üzerine mil tutucu parçaların montajı yapılmıştır. Ardından z ekseni için hareket kontrolünü sağlayacak olan trapez miller ve somunları yerleştirilip, üst taraftan sabitlenmiştir. Yuvalarına yerleştirilen tekerlek ve lineer rulmanlardan sonra $\mathrm{x}, \mathrm{y}$ ve $\mathrm{z}$ eksenindeki indüksiyon ile sertleştirilmiş kromlu çelik miller yerleştirilmiştir. Alüminyum sigma profillere motor tutucu, mil tutucu, kasnak tutucu parçalar da sabitlenmiştir. Eksenlerin montaj1 sonrası görüntü Şekil 6'da gösterilmiştir.

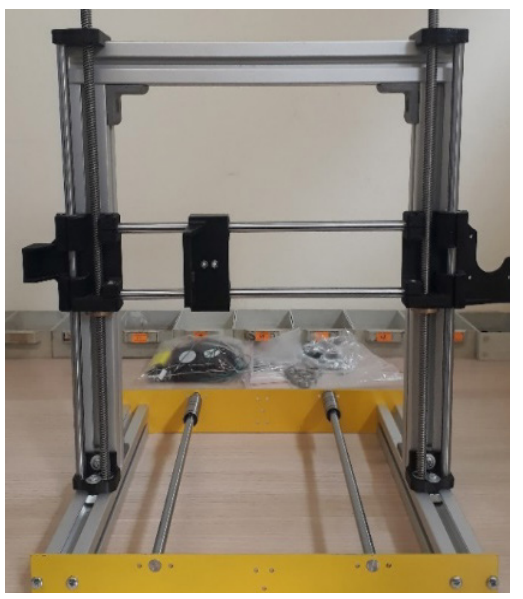

Şekil 6. Eksenlerin montajı sonrası görüntü.

Motorlardan gelen hareketi millere aktaran uygun kasnakların montajı yapılmıştır. Sistemde 3 adet motor kasnağı, 2 adet mil kasnağı ve 2 adet avare kasnak kullanılmıştır. Zamanlama kayışı ile birlikte montajı yapılmıştır. Kasnak ve kayışlar Şekil 7'de gösterilmiştir.
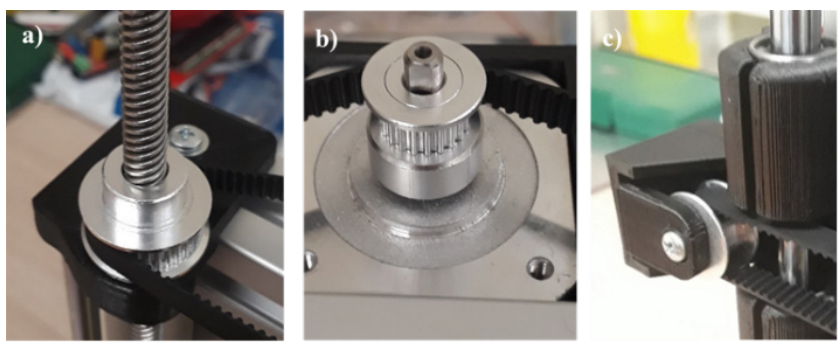

Şekil 7. Kayış kasnak düzeneği, a) trapez mil kasnağ1, b) motor mili kasnağ $1, \mathrm{c}$ ) avare kasnak

Kaynak fikstürünün montajı

Kaynak tablası, 1sı iletim katsayısı yüksek olan malzemeden hazırlanmış olup çeşitli geometrileri ile birlikte yüksek 1s1 girdisini azaltacak niteliktedir. Fikstür grubunun 
temelinde 230x230 mm kesitinde ve $3 \mathrm{~mm}$ kalınlığında siyah sac bulunmaktadır. Bu malzeme fikstürün dayanımını sağlamak için kullanılmıştır. Yukarı doğru çıkıldıkça 4 adet yatak yardımıyla $10 \mathrm{~mm}$ boşluk bırakılmıştır. Bu boşluk hem elektrik yalıtımı hem de 1sı girdisini azaltmak üzere tasarlanmıştır. Üst katmanda 230x230 mm kesitinde ve 1.5 mm kalınlığında alüminyum AA1050 alaşımı kullanılmıştır. Burada kaynak bölgesinden gelen 1sıyı hızlı bir şekilde d1şarı atmak önemli bir husustur. Aynı zamanda ani soğumayı da önlemek gerekmektedir. Kaynak işlemi, haddelenmiş pirinç malzeme üzerine yapılacaktır. Daha önceki yapılan çalışmalara göre [10], kaynak fikstüründeki pirinç malzeme, hem 1sı girdisini azalmaktadır. Ayıca kaynak yapılan parçanın da fikstüre yapışmasını engellemektedir. Alüminyum ve pirinç levha ölçüleri Şekil 8'de gösterilmiştir.

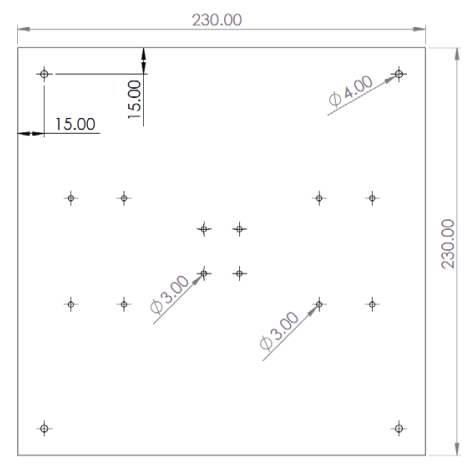

Şekil 8. Alüminyum, çelik ve pirinç malzemelerinde imal edilen levhaların teknik çizimi

Fikstürün en üst kısmında pabuç olarak 5 mm kalınlığında AA2024 alaşımı kullanılmıştır. Bu pabuçlar kaynak yapılan parçanın hem 1sı girdisini azaltacak, hem de fiziksel olarak parçaya temas edip çarpılmasını önleyecektir. Bu pabuçlar 2. kattan itibaren civatalar ile sabitlenmiştir. Tüm fikstür katları köşelerden, pabuçlar ise orta bölümden vidalanmıştır. Kaynak fikstürü prototipi Şekil 9'da gösterilmiştir.

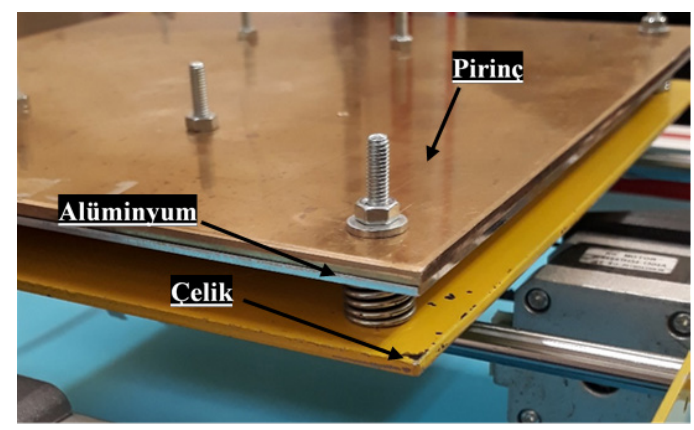

Şekil 9. Alüminyum, çelik ve pirinç malzemelerden imal edilen levhalar

\section{Kaynak torç tutucu montajl}

Kaynak torcunun tasarımında hareketli açı veren ve gerekli kodlamalar dahilinde çeşitli hareketler (zig-zag vb.) yapabilen bir sistem tasarlanmıştır. Bu açı kaynatılan malzemenin kalınlığına ve cinsine göre değişebilmektedir. Ark boyu ve kararlılığının sağlıklı olabilmesi için torç açısının iyi bir şekilde ayarlanması gerekmektedir.

Kaynak torcu montajinda $\mathrm{x}$ eksenine sabit kayar sistem kullanılmıştır. Bu parçaya M5 civata ve somun kullanılarak kaynak torcunu tutan parça monte edilmiştir. Kaynak torcunu tutan parçada, nozulu sıkması için yine M5 cıvata ve somun kullanılmıştır. Tasarlanan ve monte edilen torç tutucu Şekil 10'da gösterilmiştir.

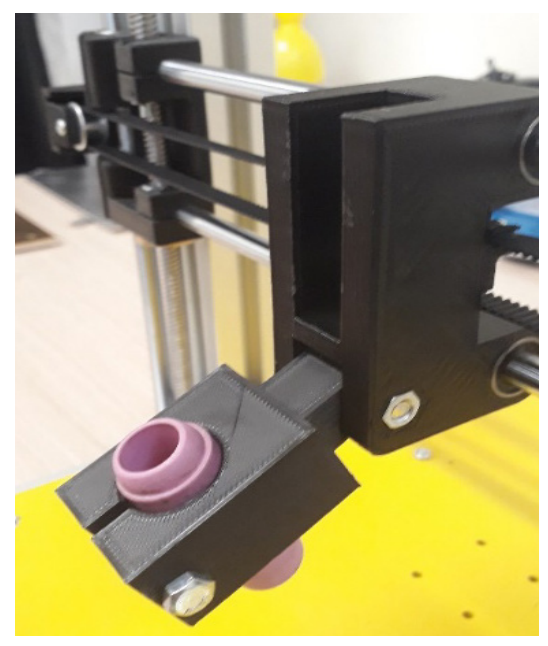

Şekil 10. Tasarlanan ve monte edilen torç tutucu

\section{TIG Kaynak Mekanizması Prototipinin Elektronik Montajı}

Elektronik montajda, adım motor, arduino ve ramps bağlantıları, limit elemanları, güç kaynağı elemanları ve LCD ekran elemanlarının montajları tamamlanmıştır. Elektronik montaj kendi arasında, adım motor ve sürücü bağlantısı, Arduino Ramps bağlantısı, limit anahtarlarının bağlantısı ve LCD kontrol ekranının bağlantısı başlıklarına ayrılmaktadır.

\section{NEMA 17 Adım Motor ve Sürücü Bağlantısı}

Adım motorlar çalışmada NEMA 17 olarak kullanılmıştır. Bu motorlar güçlü ve hızlı motorlardır. Sistemde motor sürücüsü olarak A4988 motor sürücüler kullanılmıştır. Motor sürücüler Arduino ve Ramps kartları ile doğrudan bağlantı yapılmıştır. Şekil 11'de motor sürücü ramps kart bağlantısı görülmektedir. 

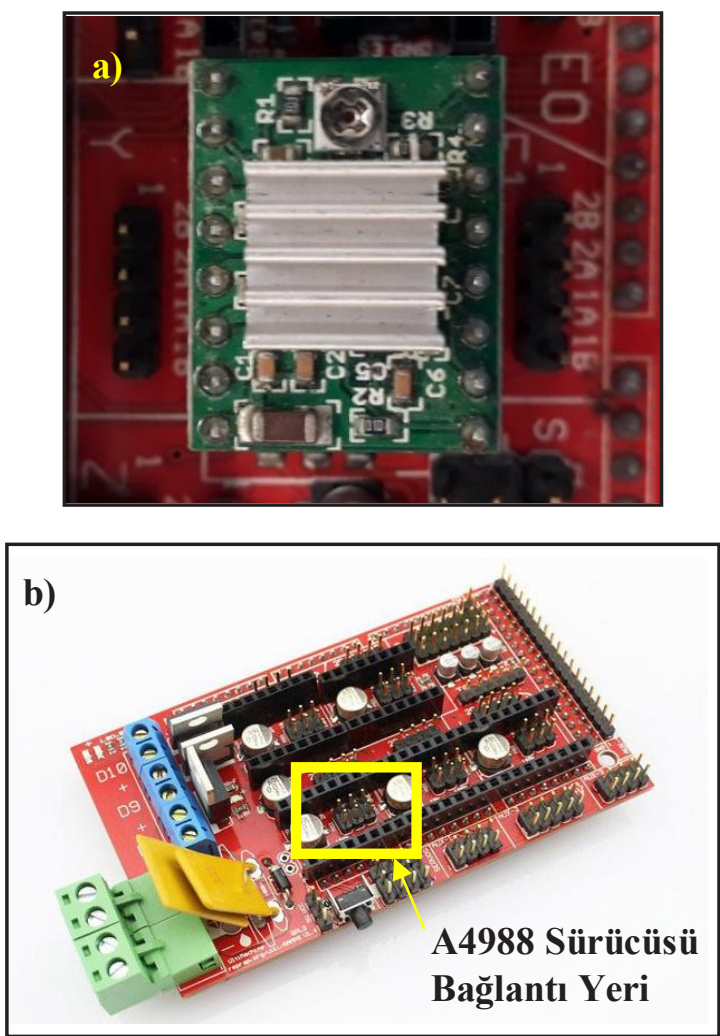

Şekil 11. a) Motor sürücüsü ve b) Ramps kart bağlantıs1

3B yazıcılar genelinde NEMA 17 motorlar kullanılmaktadır. Bunun bize getirdiği kolaylık sistemin ekstrüder motorları için kullanım kolaylığıdır. Arduino ve Ramps kartlarında standart NEMA 17 desteği ve çıkışları yer almaktadır. Aynı şekilde diğer girişlerde özel olarak desteklenmektedir.

Çalışmada kullanılan NEMA 17 motorlar 4 kablolu motorlardır. Bu 4 çıkış kablosu doğrudan A4988 adım motor sürücü üzerindeki çıkışlara bağlanmıştır. Şekil 12 'de motor sürücü ile NEMA 17 motorlar arası bağlantı şeması görülmektedir.

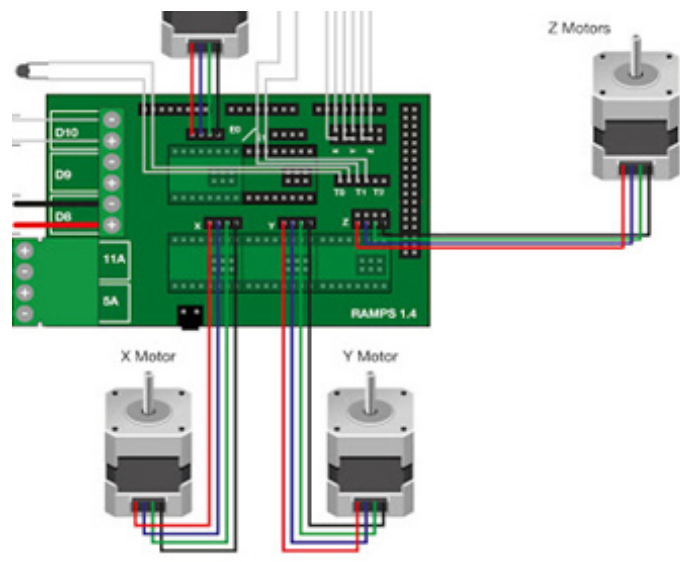

Şekil 12. NEMA 17 motorlar arası bağlantı şeması

\section{Arduino Ramps Bağlantısı}

Ramps Arduino; 3B yazıcılarda oldukça sık kullanılan bir kontrol kartıdır. Arduino Mega modeli veya benzer pin dizilimine sahip bir çok kart ile beraber kullanılabilir olan Ramps, shield yapısı sayesinde Arduino Mega'nın direk olarak üzerine oturtularak kullanılabilir. Ürün üzerine 5 adet A4988 motor sürücü kartı takılarak uygun step motorların kontrolleri sağlanabilir. Arduino Ramps bağlantısı Şekil 13 ’te gösterilmiştir.

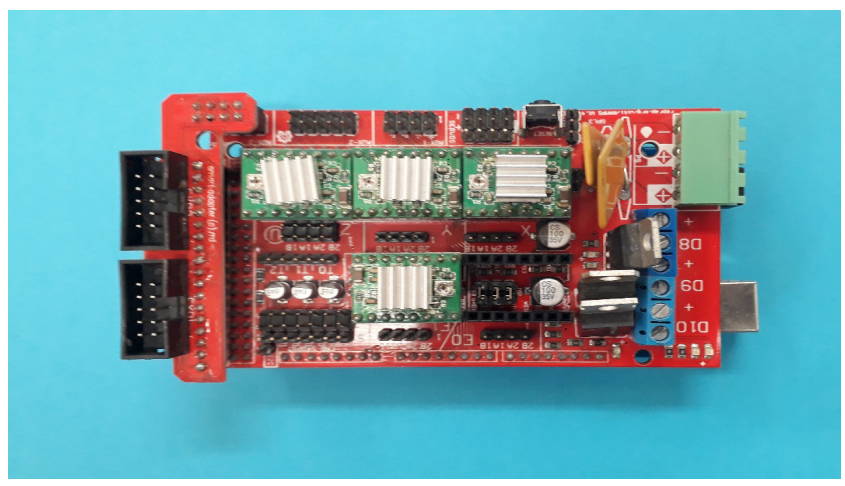

Şekil 13. Arduino Ramps bağlantısı

\section{Limit (Sınırlayıcı) Anahtarlarının Bağlantısı}

Arduino Ramps kartı üzerinde sınırlayıcı anahtar bağlanabileceği çıkışlar yer almaktadır. Burada dikkat edilmesi gereken nokta ise kart üzerinde ikili sıralı yer alan erkek jumper çıkış uçlarına artı (+) ve eksi (-) uçlara dikkat edecek şekilde bağlantı yapılmalıdır. Aynı şekilde bir diğer önemli nokta ise bağlantılar arasında bir boşluk bırakarak bağlantı yapılmalıdır. Arduino Ramps ve sınırlayıcı anahtar bağlantıları Şekil 14’te gösterilmiştir.

a)

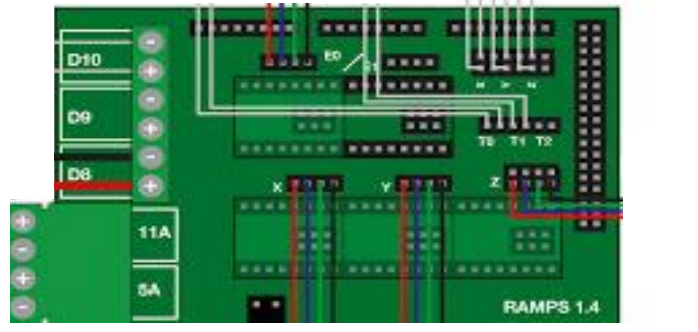




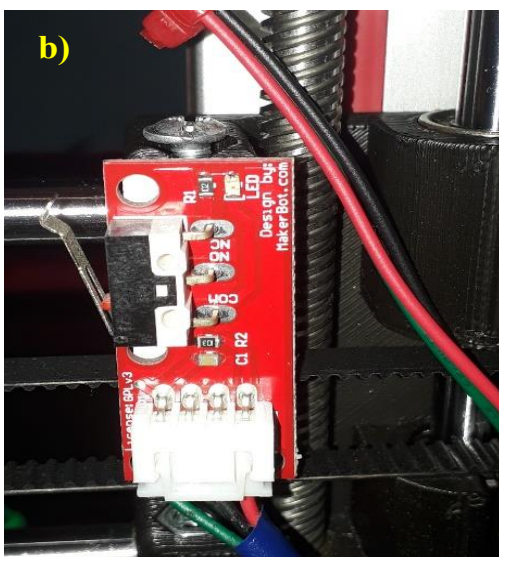

Şekil 14. a) Arduino Ramps ve sınırlayıcı anahtar bağlantı şeması b) Sinırlayıcı anahtar

\section{LCD Kontrol Ekraninin Bağlantısı}

Çalışmada bilgisayar bağlantısı olmadan yazıcıyı kontrol etmek amaciyla ve yazıcının bilgilerini kontrol edebilmek amacıyla LCD kontrol ekranı kullanılmıştır. LCD ekran doğrudan Arduino Ramps kartı üzerinde standart olarak bulunan çıkışlara bağlanmıştır. LCD ekran aynı zamanda üzerinde bulunan kart okuyucu sayesinde hafıza kartı içerisine kaydedilen yazdırma işlemini de okuyabilmektedir. Şekil 15'de Arduino Ramps kartı ve LCD ekran verilmiştir.
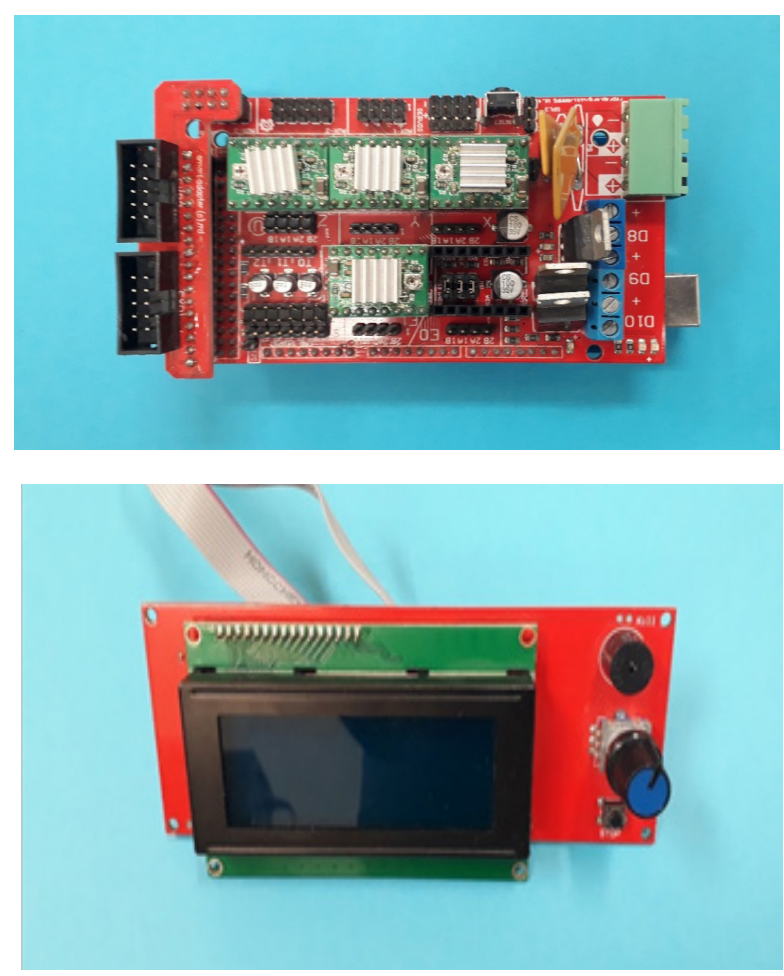

Şekil 15. a) Arduino Ramps ve LCD ekran bağlantıları, b) Çalışmada kullanılan LCD ekran modeli

\section{Kontrol Yazılımları Kurulumu}

Çalışmada 3B yazıcı kontrolü amacıyla Arduino kart ve bileşenleri kullanılmıştır. Programlama amacıyla da Arduino tabanı üzerinde gelişme gösterilmiş ve yazılım olarak da Arduino yazılımı ile kart programlanmıştır. Ayrıca sürücü ve motor testleri için Repetier-Host programı kullanılmıştır.

Arduino tabanlı kartlar arduino yazılımı ile programlanır. Çalışmada programlama için yine Arduino programı kullanılmıştır. Kart programlanırken kullanılan Arduino program ekranı Şekil 16'da görülmektedir.

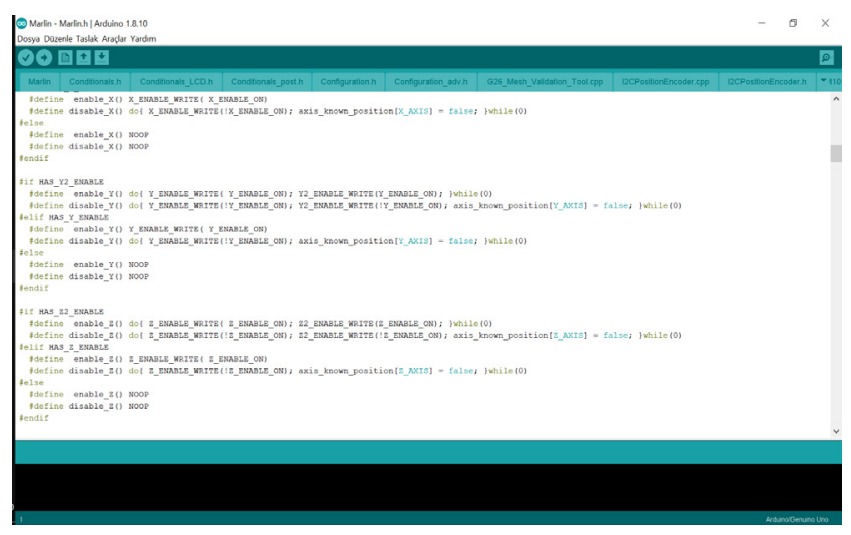

Şekil 16. Arduino program ekranı

Arduino yazılımları açık kaynaklı 3B yazıcılarda çok sık kullanılan programlama ve kontrol yazılımlarıdır. Kontrol kartı Ramps ile çoğaltılarak bütün birimleri üzerine almaktadır ve yazılım ise bu kartı tamamıyle desteklemektedir. Açık kaynaklı 3B yazıcıların kullandığı standart yazılım firmanın internet sitesi üzerinde yer almaktadır. Marlin sitesi içerisinde firmware standart dosyası indirilerek üzerinde 3B yazıcı ile ilgili düzenlemeler yapılarak devam edilmiştir. Programlama ve test aşaması Şekil 17'de gösterilmiştir.

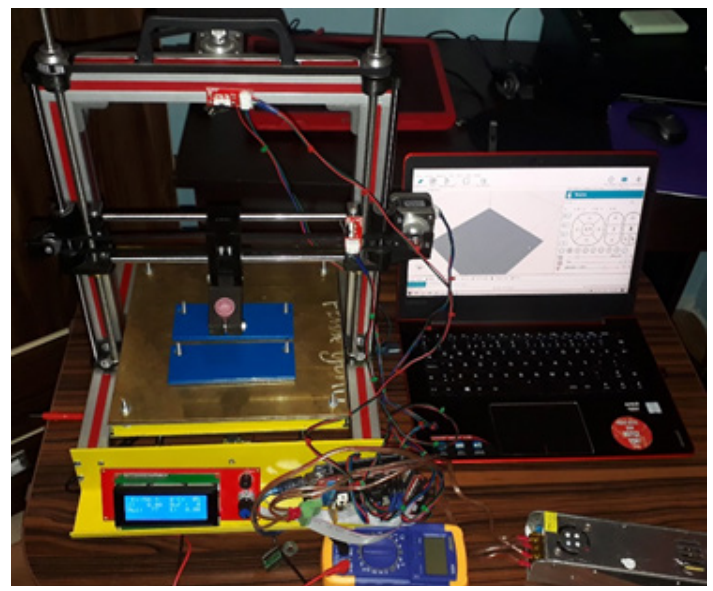

Şekil 17. Programlama ve test aşaması 


\section{SONUÇLAR}

$\mathrm{Bu}$ çalışmada hafif ve dayanıklı bir iskelet ile beraber 3 eksendeki hareketi sağlayacak çeşitli güç ve güç aktarım elemanları kullanılmıştır. TIG kaynak hareketinin titreşimini azaltmak ve dikiş performansını arttırmak için çeşitli sönümleyici elemanlar eklenmiştir. Motordan çıkacak güç bağlantı elemanları ile hareketi iletip ve x, y ve z eksenlerindeki kaynak hareketini sağlamıştır. Bu eksenlerdeki kaynak hareketi, dikiş tasarımındaki G kod verileri ile sağlanmıştır. Kaynak tablası, 1sı iletim katsayısı yüksek olan malzemeden hazırlanıp çeşitli geometrileri ile birlikte yüksek ısı girdisini azaltmak için imal edilmiştir.

Fikstür, ince ve hassas malzemelerin kaynak işlemini 3B yazıcı tekniği ile gerçekleştirip, kaynaktaki dikiş sağlaml1ğını, ark kararlığını ve gerekli nüfuziyeti oluşturabilmektedir. Sistemdeki x ve y ekseni kaynak torcunun düzlem üzerindeki dikiş hareketlerini ve kaynak hızının kontrolünü sağlamıştır. Bu sistem birleştirilecek parçalar üzerinde sadece lineer bir kaynak dikişi atmayıp, geleneksel hareketlerinden farklı olarak 3B yazıcı sistemindeki eksen hareketlerine bağlı dikiş türleriyle de kaynaklı birleştirmeler yapabilecektir. Sistemdeki z ekseni ise kaynaktaki ark boyunu ayarlayarak ark kararlılığını sağlamak üzere tasarlanmiştır.

\section{TEŞEKKÜR}

2209-A proje kapsamında verdiği finansal destekten ötürü TÜBİTAK Bilim İnsanı Destekleme Daire Başkanlığına (BİDEB) sonsuz şükranlarımızı sunarız.

\section{KAYNAKLAR}

[1] M. Kalender, Y. Bozkurt, S. Ersoy, S. Salman, "Product Development by Additive Manufacturing and 3D Printer Technology in Aerospace Industry", Journal of Aeronautics and Space Technologies, Vol. 13, No. 1, pp. 129-138, Jan. 2020.

[2] M. Kalender, S.E. Kılıç, S. Ersoy, Y. Bozkurt, S. Salman, “Additive Manufacturing and 3D Printer Technology in Aerospace Industry", 2019 9th International Conference on Recent Advances in Space Technologies (RAST), Istanbul, Turkey, 2019.

[3] E. Karayel, Y. Bozkurt. "Additive manufacturing method and different welding applications", Journal of Materials Research and Technology, Volume 9, Issue 5, pp. 11424-11438, 2020.

[4] Tülbentçi K. Gedik Eğitim Vakfı Kitapları MIG-MAG Eriyen Elektrod ile Gazaltı Kaynağı. Türkiye, 1990.
[5] Shelwatker A, Madhusudhan G, Gokhale A. "Gas Tungsten Arc Welding Studies on Similar and Dissimilar Combinations of Al-Zn- Mg Alloy RDE 40 and Al-Li Alloy 1441". Sci Technol Weld Joining, 352-61, 2002.

[6] Kahraman N, Durgutlu A, Gülenç B. "316 L Paslanmaz Çeliğin TIG Kaynağında Koruyucu Argon Gazına Hidrojen İlavesinin Kaynak Bölgesi Tane Morfolojisine Etkilerinin Araştırılması”. G.Ü.T.E.F. Politeknik Dergisi, Cilt 7, 223 228, 2004.

[7] Kou S, Le Y, "Nucleation Mechanism and Grain Refining of Weld Metal". Weld Journal, 65-70, 1986.

[8] Suresh M, Krishna B, Venugopal P, Prasad K. "Effect of Pulse Frequency in Gas Tungsten Arc Welding of Powder Metallurgical Preforms". Science and Technology of Welding \& Joining, 9, 4, 362-368, 2004.

[9] Kumar T. "Influences of Pulsed Current Tungsten Inert Gas Welding Parameters on the Tensile Properties of AA 6061 Aluminium Alloy". Materials and Design, 28 2080-2092, 2007.

[10] H. Ulupınar, M. Kalender, E. Oruç, Y. Bozkurt, "TIG Kaynak Tekniği ile Birleştirilen Farklı Boyuttaki Malzemeler İçin Portatif Fikstür Tasarımı ve Geliştirilmesi”, Uluslararası Fen Matematik ve Mühendislik Bilimleri Kongresi, İzmir - Türkiye, 2019.

[11] Modenesi P, Apolinaaria R, Pereira M. "TIG Welding with Single Component Fluxes”. Journal of Materials Processing Technology, 99, 260-265, 2000.

[12] Gürcan M. ,TIG Kaynağı SEGEM (Sanayi Eğitim ve Geliştirme Merkezi Müdürlüğü. Ankara, 1987.

[13] TIG Kaynak Diyagramı Gösterimi www.diagramma.battistifano.it/diagram/tig-welding-diagram (20.02.2020)

[14] Eşme U. Effect of Pool Geometry on the Quality of TIG Welded Joints. Doktora Tezi, Çukurova Üniversitesi, Fen Bilimleri Enstitüsü, 2006.

[15] Kim S, Son S, Kim G, Kim Y, Kim S. "A study on relationship between process variables and bead penetration for robotic CO2 arc welding". Journal of Materials Processing Technology, 136, 139-145, 2003.

[16] M. Kalender, S.E. Kılıç, Y. Bozkurt, S. Salman, A. Turker, "Design and Development of Portable Fixture for Various Dimensions Specimens Joining by Friction Stir Welding”, Orta Doğu Uluslararası Multidisipliner Çalışmalar Konferansı, Beyrut / Lübnan, 2019.

[17] Murugan N, Gunaraj V. "Prediction and control of weld bead geometry and shape relationships in submerged arc welding of pipes". Journal of Materials Processing Technology, 168, 478-487, 2005.

[18] Aidun D, Martin A. "Effect of Sulfur and Oxygen on Weld Penetration of High-Purity Austenitic Stainless Steels". JMEPEG, 6, 496-502, 1997. 